\title{
A STUDY ON INFECTIOUS DISEASE BURDEN AND ASSESSMENT OF ADVERSE DRUG REACTIONS AMONG TYPE- II DIABETES MELLITUS SUBJECTS
}

\author{
Adarsh Mathew *, Bharathi DR, Abubaker Siddiq, Akza K Alex, Tejaswini SM \\ SJM College of Pharmacy, Chitradurga-577502,
}

Article Info: Received 20 April 2019; Accepted 17 May. 2019

DOI: https://doi.org/10.32553/jbpr.v8i3.596

Address for Correspondence: Adarsh Mathew, M.Pharm Student, SJM College of Pharmacy, Chitradurga

Conflict of interest statement: No conflict of interest

\section{ABSTRACT:}

Introduction: People with diabetes are more prone to development of infections. Elevated blood sugar levels enervate the patient's immune system and make the patient vulnerable to infections.Assessing the prescription patterns assure quality medical care by providing feedback to the prescribers.

Objectives: To assess the prevalence and the prescription pattern of antibiotics in infections associated with type II diabetes mellitus along with their quality of life. To assess the Adverse Drug Reactions associated with treatment of type-II diabetes mellitus.

Materials and Methods: This prospective observational study was conducted in the General Medicine Department of Basaveshwara Medical College Hospital and Research Centre, Chitradurga for a period of 10 months.

Results: In this study, a total of 300 diabetic subjects were included, out of which, 192 subjects were having infectious diseases. This study reveals association between infection and diabetes with a prevalence rate of $64 \%$. The most commonly prescribed antibiotic was found to be ceftriaxone. The quality of life of the diabetic subjects associated with infections was found to be displeasing when assessed with a validated questionnaire.

Conclusion: The study shows a higher rate of prevalence of infectious disease among diabetic subjects. It is suggested to conduct more studies on this topic.

Keywords: Diabetes mellitus; Infectious diseases; Adverse drug reactions; Burden of disease.

\section{INTRODUCTION}

According to studies, the incidence of diabetes have increased surprisingly during $30 y$ rs. $^{1}$ In accordance with International Diabetes Federation (IDF), 400 million persons are estimated to have diabetes in 2014 and it is expected to rise up to 590 million by $2035 .^{2}$

People with diabetes are more prone to development of infections. Elevated blood sugar levels enervate the patient's immune system and make the patient susceptible to infections. Furthermore, diabetes related issues like nerve damage and decreased blood flow to the extremities can also increase the chances of infections. $^{3}$
Infection- related mortality is increased among diabetics when compared to non-diabetics, but only with the people having co-morbid cardiovascular diseases. ${ }^{4}$

Antibiotics are the drugs often prescribed for patients in intensive care and surgical departments. ${ }^{5}$ Assessing the prescription patterns assure quality medical care by providing feedback to the prescribers. ${ }^{6}$ Appropriate antibiotic prescriptions are an important component in quality of life, infection control and cost of efficacy. ${ }^{4}$

It is requisite to accomplish an exploration on infectious disease burden and assessment of adverse drug reactions among type 2 Diabetes 
Adarsh Mathew et al., Journal of Biomedical and Pharmaceutical Research

Mellitus (DM) subjects in compliance with above statements.

\section{MATERIALS AND METHODS}

Study Site: The study has been conducted in General Medicine Department, Basaveshwara Medical College Hospital and Research Centre, Chitradurga.

Study design: It is a prospective observational study.

Study period: The study was conducted for a period of ten months from 2018 to 2019.

Study subjects: The study included the subjects who meet the following criteria

\section{Inclusion Criteria:}

- Both genders were included in the study.

- Both rural and urban subjects were included.

- $\quad$ Subjects having type II DM were included.

- Age group: 20-70 years.

Exclusion Criteria:

- Subjects having DM with hypertension were excluded.

- $\quad$ Subjects having DM with TB were excluded.

Sources of data:

- Demographics, medication and medical history were collected from the patient profile form and their prescriptions.

\section{Study procedure:}

The study was initiated after obtaining the ethical clearance from Institutional Ethics Committee (IEC). Subjects who have satisfied the above study criteria have been recruited into the study. All the subjects were explained regarding the study and Informed Consent Form was obtained. The demographic details, medical information, medication data and other relevant information were documented in a pre structured data collection form. A validated questionnaire was used to assess the the quality of life of the subjects.

\section{Statistical Analysis}

The data were entered in Microsoft Excel sheets and analysis has been done by Social Programme Scientific Software (SPSS) version 24. The data was analyzed by Descriptive methods (Mean).

\section{RESULTS}

A total of 300 diabetic patients were enrolled into the study. The data of the subjects were analyzed and presented as follows;

\section{Prevalence according to infections}

Prevalence of infectious conditions among 300 patients were classified as cellulitis (19.0\%), diabetic foot ulcer $(29.0 \%)$, sepsis (1.2\%), gangrene (0.6\%), asthma (0.6\%), pneumonia (8.0\%), low RTI (1.3\%), upper RTI (0.6\%), nephropathy (0.6) and UTI (2.6\%). The results are shown in table no.1

Table 1: Prevalence of Infectious Conditions:

\begin{tabular}{|l|l|l|}
\hline Sr. No. & Infections & Prevalence (\%) \\
\hline 1 & Cellulitis & 19.0 \\
\hline 2 & Diabetic foot ulcer & 29.0 \\
\hline 3 & Sepsis & 1.2 \\
\hline 4 & Gangrene & 0.6 \\
\hline 5 & Asthma & 0.6 \\
\hline 6 & Pneumonia & 8.0 \\
\hline 7 & Lower RTI & 1.3 \\
\hline 8 & Upper RTI & 0.6 \\
\hline 9 & Nephropathy & 0.6 \\
\hline 10 & UTI & 2.6 \\
\hline
\end{tabular}

\section{Prescription Pattern of antibiotics}

Among the192 prescriptions, 358 antibiotics were prescribed. The most frequently prescribed antibiotics were ceftriaxone $89(24.9 \%)$ followed by amikacin $43(12.1 \%)$ and the least prescribed were cefuroxime $02(0.5 \%)$ and ampicillin $02(0.5 \%)$. The results are shown in table no.2 and graphically represented in fig.no.2. 
Adarsh Mathew et al., Journal of Biomedical and Pharmaceutical Research

Table 2: Prescription pattern of antibiotics ( $n=358$ )

\begin{tabular}{|c|c|c|c|c|}
\hline Sr. No. & Type of therapy & Drugs & Frequency & Percentage (\%) \\
\hline \multirow{9}{*}{1} & \multirow{9}{*}{ Mono therapy } & Clindamycin & 09 & 2.5 \\
\hline & & Amikacin & 43 & 12.1 \\
\hline & & Azithromycin & 17 & 4.8 \\
\hline & & Ceftriaxone & 89 & 24.9 \\
\hline & & Metronidazole & 18 & 5.0 \\
\hline & & Meropenum & 11 & 3.1 \\
\hline & & Cefuroxime & 02 & 0.5 \\
\hline & & Ampicillin & 02 & 0.5 \\
\hline & & Cefixime & 05 & 1.4 \\
\hline \multirow{9}{*}{2} & \multirow{9}{*}{ Dual therapy } & Ceftriaxone + Sulbactum & 23 & 6.4 \\
\hline & & Pipracillin + Tazobactum & 27 & 7.5 \\
\hline & & Ceftazidine + Tazobactum & 21 & 5.9 \\
\hline & & Cefotaxime + Sulbactum & 24 & 6.7 \\
\hline & & Cefuroxime + Sulbactum & 04 & 1.1 \\
\hline & & Ofloxacin + Ornidazole & 04 & 1.1 \\
\hline & & Amoxicillin + Clavunic acid & 32 & 8.9 \\
\hline & & $\begin{array}{l}\text { Sulfamethaxazole } \\
\text { Trimethoprim }\end{array}$ & 06 & 1.7 \\
\hline & & Ceftriaxone + Tazobactum & 21 & 5.9 \\
\hline \multicolumn{3}{|l|}{ TOTAL } & 358 & 100 \\
\hline
\end{tabular}

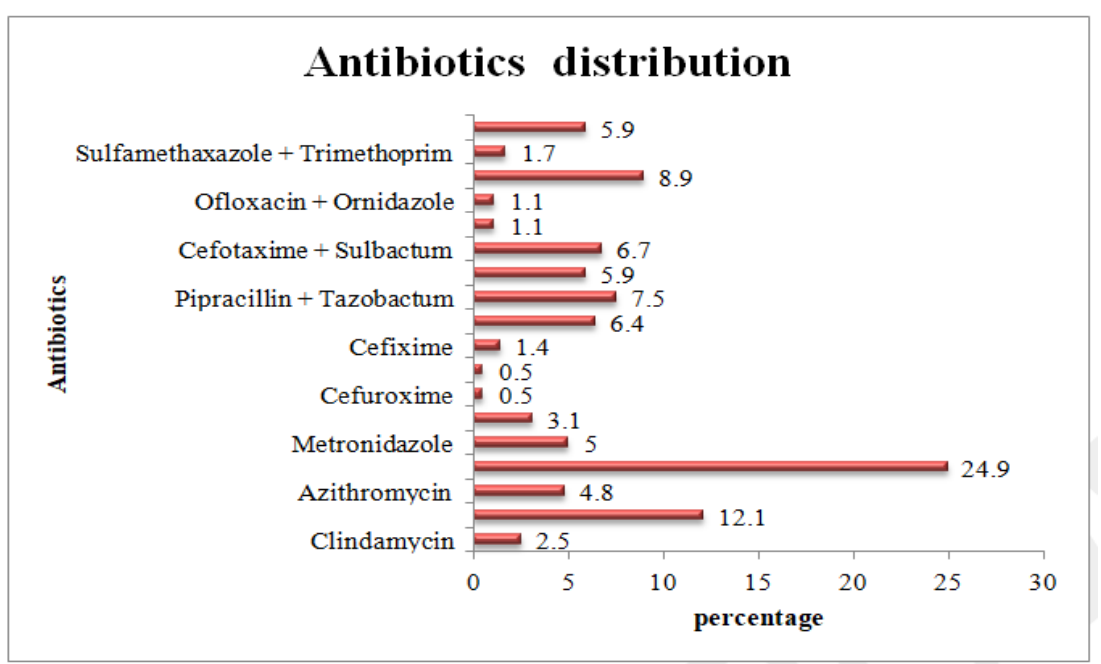

Figure 2: Prescription pattern of antibiotics 
Adarsh Mathew et al., Journal of Biomedical and Pharmaceutical Research

\section{Quality of life assessment}

Quality of life of the diabetic patients associated with infections was assessed by a validated questionnaire and the response given by subjects was presented as follows;

Response to the question: "How often do you worry about whether you will miss work?"

When the subjects were asked about how much they are worried about missing work due to their health conditions, 93(48.4\%) replied that they often do and 04(2.1\%) replied that they never. The results are shown in table no. 3 and graphically represented in fig no. 3

Table 3: Response to the question: “How often do you worry about whether you will miss work?"

\begin{tabular}{|l|l|l|l|}
\hline Sr. No & Answer given & Frequency & Percentage \\
\hline 1 & Never & 04 & 2.1 \\
\hline 2 & Very rarely & 32 & 16.6 \\
\hline 3 & Sometimes & 58 & 30.2 \\
\hline 4 & Often & 93 & 48.4 \\
\hline 5 & All the time & 05 & 2.7 \\
\hline Total & & $\mathbf{1 9 2}$ & $\mathbf{1 0 0}$ \\
\hline
\end{tabular}

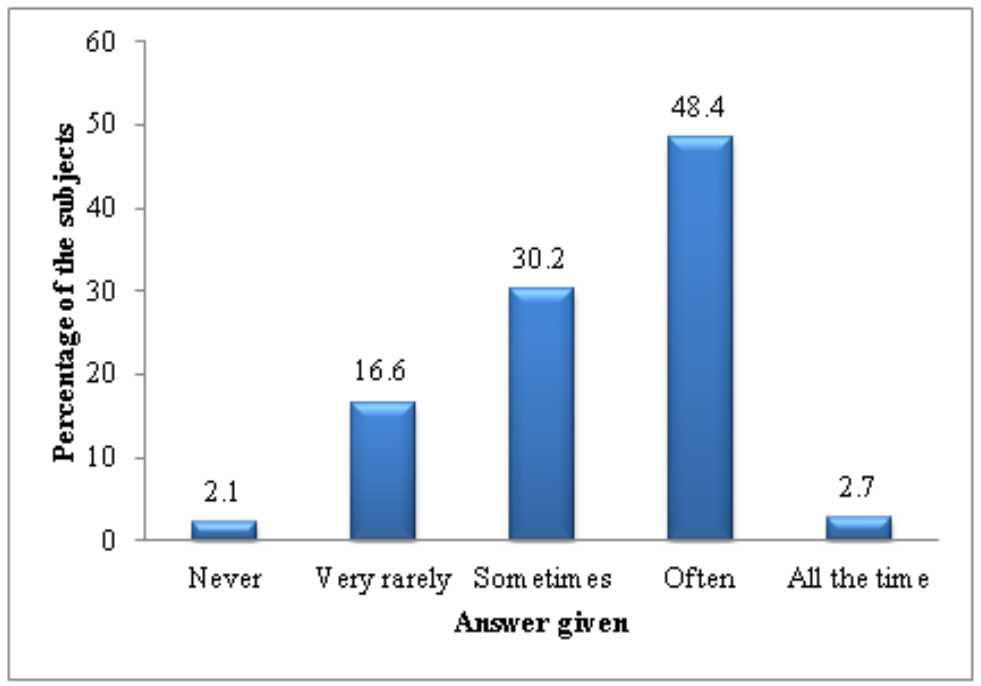

Figure 3: Response to the question: "How often do you worry about whether you will miss work?

Response to the question: "How often do you have a bad night's sleep because of diabetes?"

When the subjects were asked about the impact of diabetes to their sleep, 81(42.2\%) replied that they are affected very rarely and $04(2.0 \%)$ replied that they are affected all the time. The results are shown in table no. 4 and graphically represented in fig no. 4.

Table 4: Response to the question: “How often do you have a bad night's sleep because of diabetes?”

\begin{tabular}{|l|l|l|l|}
\hline Sr. No & Answer given & Frequency & $\begin{array}{l}\text { Percent } \\
\text { age }\end{array}$ \\
\hline 1 & Never & 17 & 8.8 \\
\hline 2 & Very rarely & 81 & 42.2 \\
\hline 3 & Sometimes & 61 & 31.8 \\
\hline 4 & Often & 29 & 15.2 \\
\hline 5 & All the time & 04 & 2.0 \\
\hline Total & $\mathbf{1 9 2}$ & $\mathbf{1 0 0}$ \\
\hline
\end{tabular}


Adarsh Mathew et al., Journal of Biomedical and Pharmaceutical Research

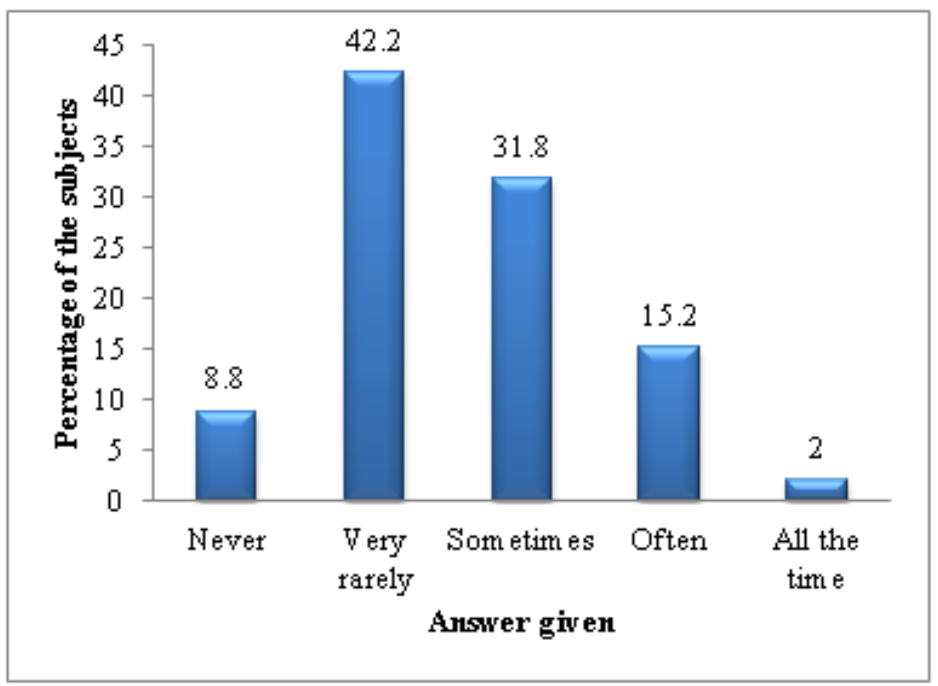

Figure 4: Response to the question: “How often do you have a bad night's sleep because of diabetes?"

Response to the question: "How satisfied are you with your sex life?"

When the subjects were asked about their sex life, 86(44.8\%) were moderately satisfied and $17(8.8 \%)$ were very dissatisfied. The results are shown in table no. 5 and graphically represented in fig no. 5

Table 5: Response to the question: "How satisfied are you with your sex life?"

\begin{tabular}{|l|l|l|l|}
\hline Sr. No & Answer given & Frequency & Percentage \\
\hline 1 & Very satisfied & 41 & 21.3 \\
\hline 2 & Moderately satisfied & 86 & 44.8 \\
\hline 3 & Neither & 29 & 15.2 \\
\hline 4 & Moderately dissatisfied & 19 & 9.9 \\
\hline 5 & Very dissatisfied & 17 & 8.8 \\
\hline Total & $\mathbf{1 9 2}$ & $\mathbf{1 0 0}$ \\
\hline
\end{tabular}

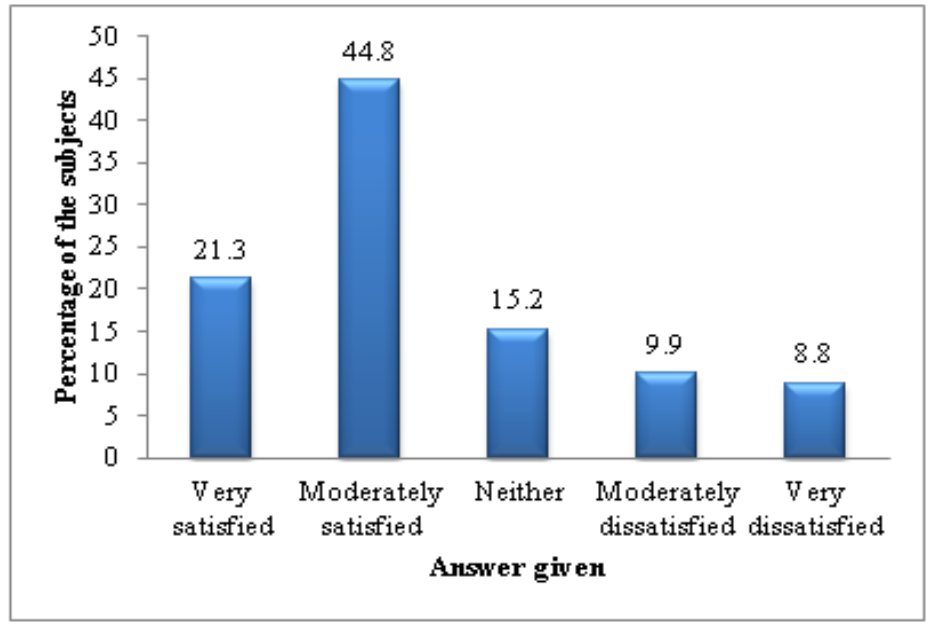

Figure 5: Response to the question: "How satisfied are you with your sex life?"

Response to the question: "How satisfied are you with the burden your diabetes is placing on your family?" Among the subjects, 64(33.4\%) mentioned that they are moderately satisfied with the burden that their diabetes is placing on their family and $15(7.8 \%)$ replied that they are very dissatisfied. The results are shown in table no. 6 and graphically represented in fig no. 6 
Adarsh Mathew et al., Journal of Biomedical and Pharmaceutical Research

Table 6: Response to the question: "How satisfied are you with the burden your diabetes is placing on your family?"

\begin{tabular}{|l|l|l|l|}
\hline Sr. No & Answer given & Frequency & Percentage \\
\hline 1 & Very satisfied & 17 & 8.8 \\
\hline 2 & Moderately satisfied & 64 & 33.4 \\
\hline 3 & Neither & 45 & 23.5 \\
\hline 4 & Moderately dissatisfied & 49 & 25.5 \\
\hline 5 & Very dissatisfied & 15 & 7.8 \\
\hline Total & & $\mathbf{1 9 2}$ & $\mathbf{1 0 0}$ \\
\hline
\end{tabular}

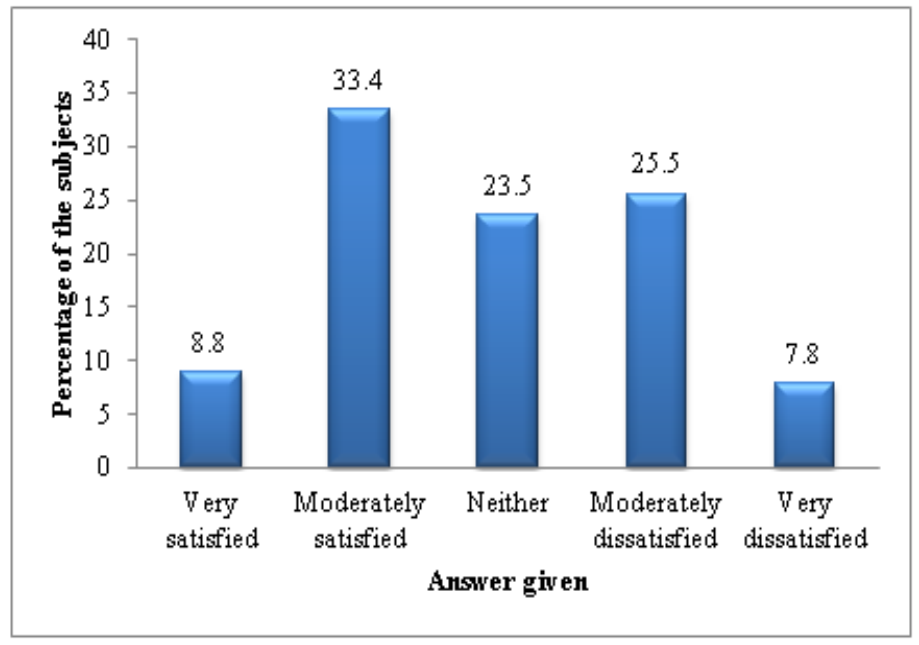

Figure 6: Response to the question: "How satisfied are you with the burden your diabetes is placing on your family?"

Response to the question: "How often do you feel physically ill?"

74 (38.5\%) subjects responded that they feel physically ill very rarely, 18 (9.4\%) replied that they never feel ill at all and $18(9.4 \%)$ replied that they feel always ill. The results are shown in table no. 7 and graphically represented in fig. No. 7

Table 7: Response to the question: "How often do you feel physically ill?"

\begin{tabular}{|l|l|l|l|}
\hline Sr. No & Answer given & Frequency & Percentage \\
\hline 1 & Never & 18 & 9.4 \\
\hline 2 & Very rarely & 74 & 38.5 \\
\hline 3 & Sometimes & 48 & 25.1 \\
\hline 4 & Often & 34 & 17.7 \\
\hline 5 & All the time & 18 & 9.4 \\
\hline Total & & $\mathbf{1 9 2}$ & $\mathbf{1 0 0}$ \\
\hline
\end{tabular}




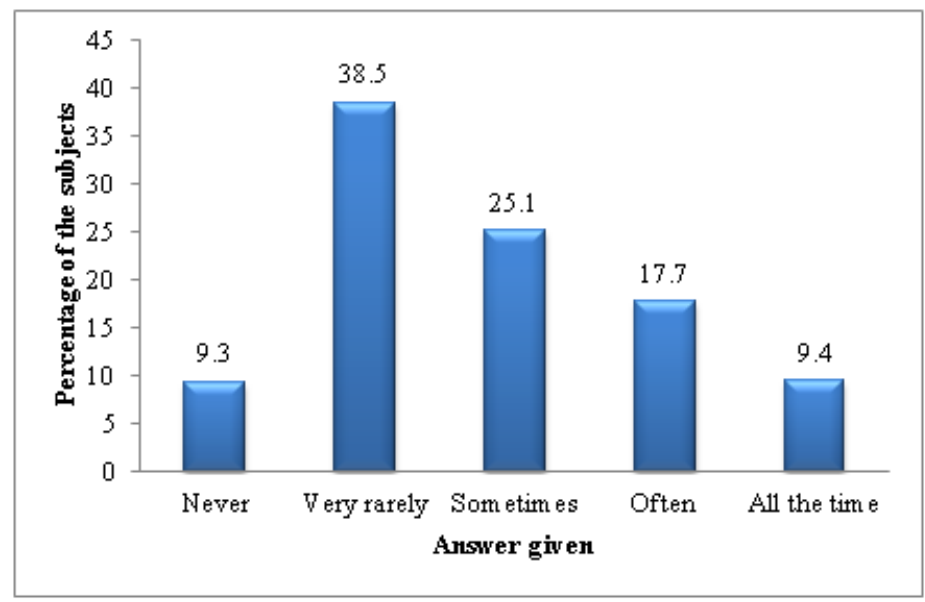

Figure 7: Response to the question: "How often do you feel physically ill?"

\section{ADRs Associated with the Treatment}

No ADRs were observed during the study time in any of the subjects.

\section{DISCUSSION}

A total of 192 subjects have been found to be suffering from infections out of which the highest incidence rate was of diabetic foot ulcer, followed by cellulitis and pneumonia. Our findings shows that prevalence of various infections associated with type II DM is 0.64 or $64 \%$ i.e., 1 in every (4.68 $\approx 5) 5$ members likely to be affected by the infections. Carey I et al., conducted a matched cohort study, to assess the risk of infections in type 1 and type 2 DM patients, in which they stated that, patients with diabetes had higher rates for all infections, with the highest incidence rates seen for bone and joint infections, sepsis, and cellulitis. They also reported that the incidence rate of infections in type $2 \mathrm{DM}$ was $1.88 .^{7}$

In our study, out of 192 subjects, $54.8 \%$ were on monotherapy and $45.2 \%$ on combination therapy. The most frequently prescribed antibiotic was found to be ceftriaxone and the most commonly prescribed anti diabetic drug was a combination of glimepride and metformin (sulfonyl urea and biguanide). Preeth $\mathbf{M}$ et al., conducted a similar study which reported that, out of the 110 subjects, $6.3 \%$ were on monotherapy and $92.7 \%$ on combination therapy. They reported that Cilastin+Imipinem combination was maximally used in the management of infections. ${ }^{5}$

Quality of life of the subjects were analyzed using a validated questionnaire, by which we concluded that majority of the subjects were not much satisfied by their present condition, which shows that diabetes have affected quality of life of the subjects negatively. Huang $\mathrm{E}$ et al., conducted a similar study on quality of life of the diabetic patients, and they concluded that, end- stage complications remains as a great burden in quality of life and they also stated that comprehensive diabetes treatments have a significant negative impact on quality of life. ${ }^{8}$

No ADRs were observed in the study subjects during the study period.

\section{CONCLUSION}

According to the analyzed results and from view of literature, the conclusions made are:

- Our findings shows that prevalence of various infections associated with type $2 \mathrm{DM}$ is 0.64 or $64 \%$ i.e., 1 in every $(4.68 \approx 5) 5$ members likely to be affected by the infections.

- The most frequently prescribed antibiotic was found to be ceftriaxone.

- Quality of life of the subjects were analyzed using a validated questionnaire, by which we concluded that majority of the subjects were not much satisfied by their present condition, which shows that diabetes have affected quality of life of the subjects negatively.

- No ADRs were observed in the study during the study period. 
Adarsh Mathew et al., Journal of Biomedical and Pharmaceutical Research

\section{ACKNOWLEDGEMENT}

It is a pleasure and privilege to express my deep sense of thanks and indebtedness to the management of SJM College of Pharmacy Karnataka, Dr. Bharathi D.R, Principal SJM College of Pharmacy and Mr. Abubaker Siddiq for giving the consent and facilities to carry out this work.

\section{REFERENCES:}

1. Ali N, Rehman S, Imran M, Hussian I, Shehbaz $\mathrm{N}$, Jamshed $\mathrm{H}$ et al. The in-practice prescribing pattern for antibiotics in the management of diabetic foot: Needs much more to be done!. J Young Pharm 2009;1(4):375.

2. Abu-Ashour W, Twells L, Valcour J, Randell A, Donnan J, Howse $P$ et al. The association between diabetes mellitus and incident infections: a systematic review and metaanalysis of observational studies. BMJ Open Diabetes Res Care 2017;5(1):1-10.

3. Thomas Z, Narendra K, Ayyappa Swamy C, Mahedravarman $P$, Senthilvelan M. Study on drug utilization,prescribing pattern and use of antibiotics in the management of diabetic foot ulcer. IJIPSR 2015;3(8):1037-49.

4. Shah B, Hux J. Quantifying the Risk of Infectious Diseases for People with Diabetes. Diabetes Care 2003;26(2):510-13.

5. Preeth $M$, Shobana J. Study on prescribing patterns of antibiotics used in the management of various infectious diseases in Andhra Pradesh. Int Res J Pharm 2011;2(7):112-15.

6. Ashok Kumar M, Nizar A, Shailaja K, Jayasutha J, Ramasamy C. A study on prescribing pattern and potential drug-drug interactions in type 2 diabetes mellitus (inpatients) in a tertiary care teaching hospital. Der Pharmacia Lettre 2011;3(4):13-19.

7. Carey I, Critchley J, DeWilde S, Harris T, Hosking F, Cook D. Risk of Infection in Type 1 and Type 2 Diabetes Compared With the General Population: A Matched Cohort Study. Diabetes Care 2018;41(3):513-21.

8. Huang $E$, Brown $S$, Ewigman $B$, Foley $E$, Meltzer D. Patient Perceptions of Quality of Life With Diabetes-Related Complications and Treatments. Diabetes Care 2007;30(10):247883.

9. Venkataraman $\mathrm{K}$, Wee $\mathrm{H}$, Leow $\mathrm{M}$, Tai $\mathrm{E}$, Lee J, Lim $S$ et al. Associations between complications and health-related quality of life in individuals with diabetes. Clin Endocrinol 2013;78(6):865-73.

10. Ijaz M, Ali S, Khan S, Hassan M, Bangash I. Urinary Tract Infection In Diabetic Patients; Causative Bacteria And Antibiotic Sensitivity. J Med Sci 2014;22(3):110-14.

11. Dutta $S$, Beg $M$, Anjoom M, Varma A, Bawa $S$. Study on drug prescribing pattern in diabetes mellitus patients in a tertiary care teaching hospital at Dehradun, Uttarakhand. Int J Med Sci Public Health 2014;3(11):1351.

12. Bettegowda S, lyengar V, Gosain V, Naik V, Vuyyuru S, Bandreddi G. Clinical profile and Spectrum of Infections in Type 2 Diabetes Mellitus Patients : A Retrospective Study from Rural Tertiary Care Hospital of South Karnataka, India. Sch J App Med Sci 2014;2 (6G):3331-36. 